\title{
¿Regular o competir? El caso de la Ley de Servicios de Comunicación Audiovisual de la República Argentina y el principio de proporcionalidad como criterio delimitador ¿Regulation or competition? The case of the Argentine Law of Audiovisual Communications Services and the Proportionality Principle as a delimiting criterion
}

\author{
ÓSCAR RAFAEL AGUILAR VALDEZ*
}

\begin{abstract}
Resumen: En este trabajo se pretende señalar la importancia del principio de proporcionalidad como un criterio jurídico válido para determinar cuándo una determinada industria debe ser regulada de modo sectorial y ex ante o cuando resulta preferible hacerlo mediante modalidades menos intrusivas como, por ejemplo, el régimen de defensa de la competencia. A estos efectos, se utilizará como ejemplo lo ocurrido en la República Argentina con la Ley de Servicios de Comunicación Audiovisual y su tratamiento por la Corte Suprema de Justicia en el caso del Grupo Clarín.
\end{abstract}

Palabras clave: competencia - regulación - servicios de comunicación audiovisual -principio de proporcionalidad - Argentina

Abstract: The purpose of this article is to highlight the importance of the
Proportionality Principle as a valid legal criterion to determine when a given
industry must be ex ante regulated by the Government through a specific
sectorial regulatory framework or whether the application of the general
antitrust and competition laws to such industry must be considered as a valid
alternative. To this ends, this article analyzes the case of the Argentinean Law
of Audiovisual Communications Services as it was treated by the Supreme
Court of Argentina in the Grupo Clarín case.

Key words: competition - regulation - audiovisual - communications services - proportionality principle - Argentina

CONTENIDO: I.INTRODUCCIÓN.- II. LIBERTAD DE EXPRESIÓN Y PROPIEDAD DE LOS MEDIOS DE COMUNICACIÓN.- III. ¿POR QUÉ REGULAR LA PROPIEDAD DE LOS MEDIOS DE COMUNICACIÓN? EL CAMBIO DEL PARADIGMA REGULATORIO.- IV. LA REGULACIÓN DE LA PROPIEDAD DE LOS MEDIOS DE COMUNICACIÓN Y EL PRINCIPIO DE ADECUACIÓN.- V. LA REGULACIÓN DE LA PROPIEDAD DE LOS MEDIOS DE COMUNICACIÓN Y EL PRINCIPIO DE NECESIDAD.- VI. LA REGULACIÓN DE LA PROPIEDAD DE LOS MEDIOS DE COMUNICACIÓN Y EL PRINCIPIO DE PROPORCIONALIDAD EN SENTIDO ESTRICTO.- VII. CONCLUSIONES.- VIII. BIBLIOGRAFÍA.

* Abogado por la Pontificia Universidad Católica Argentina, Máster en Derecho Administrativo por la Universidad Austral. Profesor de Derecho Administrativo de la Pontificia Universidad Católica Argentina, Buenos Aires. Correo electrónico: oaguilar@ebv.com.ar 


\section{INTRODUCCIÓN}

Por medio de esta colaboración pretendemos formular algunas reflexiones sobre una cuestión que es de extrema relevancia: determinar un criterio jurídico que sirva para evaluar si a una determinada actividad corresponde imponerle por vía legislativa o regulatoria sectorial y ex ante una determinada organización industrial o, si por el contrario, lo que corresponde es someterla a la competencia posible en el mercado y, en su caso, a una regulación de «mano blanda», común a todos los sectores económicos, y fundamentalmente de aplicación caso por caso, como puede ser el régimen general de defensa de la competencia (cuestión que constituye uno de los tópicos más clásicos en materia de teoría regulatoria; al respecto, véase Veljanosvki, 2006, p. 157). Para ello, tomaremos el caso de la regulación de los medios de comunicación audiovisual, tal como se planteó la cuestión en la Argentina en tiempos recientes. Sucede que el fenómeno de la globalización y, en especial, las profundas transformaciones que han tenido las técnicas y los medios de comunicación han impactado de modo relevante en el acceso de miles de personas a un bien público por naturaleza, como lo es la información. Asimismo, ha sido importante el impacto en la comunicación de manifestaciones culturales que, como tales, están destinadas a circular sin restricciones.

En este contexto, el siglo XXI muestra que, en nuestra región, los poderes públicos han tomado la decisión de proceder a regular la propiedad de los medios a través de los cuales dichos bienes son transmitidos y comunicados a la sociedad con el fin de promover su universalidad y el pluralismo de ideas. Pero esta decisión, cuya finalidad es en sí misma loable - como se verá-, no está exenta de problemas de variada índole, entre ellos, la determinación de la forma y grado de regulación que estas peculiares actividades admitirían. Al respecto, téngase en cuenta que la realización de toda actividad económica supone, por parte de sus agentes, la titularidad de «derechos de propiedad» y, por lo tanto, la posibilidad de obtener, a través de estos y bajo ciertas circunstancias, un determinado «poder de mercado». Así, tanto la regulación directa y sectorial como el régimen de protección y garantía de la libre competencia suponen, a través de técnicas y formas de intervención diferentes, establecer limitaciones sobre esos derechos de propiedad de las empresas operadoras (Viscusi \& otros, 2000, pp. 3-6). Por eso, establecer algún criterio jurídico —más allá de las conocidas disputas que sobre el particular existen en el terreno de la llamada «economía de la regulación»- que permita analizar la pertinencia de utilizar una u otra técnica de intervención pública resulta de superior importancia en la materia.

Así, sobre la base de lo que ha ocurrido en la Argentina con motivo de la sanción de la llamada Ley de Servicios de Comunicación Audiovisual 
(Senado y Cámara de Diputados de la Nación Argentina, 2009; en adelante, LSCA) ${ }^{1}$ y, en especial, en función de la validación que dicha ley mereció por parte de la Corte Suprema argentina en el caso Grupo Clarín (Corte Suprema de Justicia de la Nación Argentina, 2013; para una visión detallada de las diversas vicisitudes y posiciones debatidas en el caso, incluyendo las principales piezas presentadas en el expediente, véase, por ejemplo, Rodríguez Simón, 2013), pretendemos plantear sobre la base de un análisis fundado en los tres subprincipios que integran el llamado principio de proporcionalidad (sobre estos subprincipios véase, con especial referencia al derecho argentino, Cianciardo, 2009)— las que para nosotros son las principales cuestiones que deben ser abordadas, desde un enfoque iuspublicista, para determinar si una determinada regulación directa, sectorial y ex ante de la propiedad de los medios de comunicación es o no razonable (sobre la relación entre proporcionalidad y razonabilidad, véase Coviello, 2008) y, en su caso, si no corresponde someter a dicha actividad a una intervención estatal diferente. Téngase en cuenta, a estos efectos, que mientras que la LSCA —al establecer un régimen antitrust per se y sectorial - consideró que un determinado grado de concentración en la propiedad de medios audiovisuales supone, por sí misma, afectar el interés general, el régimen de defensa de la competencia argentino — de aplicación «horizontal» o común a toda industria (Orlanski, 2006, p. 35) —, por el contrario, no considera que un determinado «poder de mercado» o nivel de concentración económica esté destinado, per se, a afectar la competencia (Coloma, 2003, p. 362). Bajo este último régimen, la determinación de si una cierta concentración empresaria es susceptible, o no, de afectar la libre concurrencia dependerá de un análisis particular, caso por caso, y basado en estudios técnicos y económicos que deberán producirse de modo particularizado. Dicho de otra forma: a diferencia del presupuesto del que partió la LSCA, para el régimen de libre competencia argentino no existe presunción legal alguna de que un alto porcentaje de concentración o de «poder de mercado» derivará, necesariamente, en una situación que permita al operador económico abusar de tal posición de dominio, afectando, así, el interés económico general.

Repárese, además, que en el campo de la regulación audiovisual juega también un rol, paralelamente a los derechos de propiedad, la garantía de la libertad de expresión, libertad que es esencial a una moderna sociedad democrática. Todo ello le impone importantes distintivos a esta cuestión. Desde una perspectiva que tenga al hombre y a todos sus derechos como norte, no es suficiente que -como ocurre en este campo- el fin perseguido por el Estado sea elevado o de una bondad

1 De todos modos, cabe señalar que gran parte de las normas contenidas en esta ley y que serán objeto de tratamiento en esta contribución fueron ya modificadas, ya derogadas por la actual Administración mediante el decreto 267/2015 (Presidencia de la Nación Argentina, 2015). No obstante, y según nuestro entender, ello no quita la importancia del debate que se presentó sobre esas regulaciones.

¿REGULAR O

COMPETIR? EL

CASO DE LA LEY

DE SERVICIOS DE

COMUNICACIÓN

AUDIOVISUAL DE

LA REPÚBLICA

ARGENTINA Y EL

PRINCIPIO DE PRO-

PORCIONALIDAD

COMO CRITERIO

DELIMITADOR

¿REGULATION OR

COMPETITION?

THE CASE OFTHE

ARGENTINE LAW

OF AUDIOVISUAL

COMMUNICATIONS

SERVICES AND

THE PROPORTIO-

NALITY PRINCIPLE

AS A DELIMITING

CRITERION 
innegable, sino que es menester que los distintos intereses y derechos en juego sean armonizados sin que se realicen sacrificios innecesarios de derechos y recursos. En definitiva, el principio de proporcionalidad tiene, en materia de regulación de actividades privadas, un sentido y una finalidad de suma relevancia: racionalizar la intervención regulatoria (Huapaya Tapia, 2011, pp. 726-727).

\section{LIBERTAD DE EXPRESIÓN Y PROPIEDAD DE LOS MEDIOS DE COMUNICACIÓN}

El régimen interamericano de derechos humanos muestra que entre el derecho humano a la libertad de expresión y la titularidad de los medios de comunicación existe una íntima relación. Así, el artículo 13.1. de la Convención Americana de Derechos Humanos establece el llamado principio de universalidad en los siguientes términos: «Toda persona tiene derecho a la libertad de pensamiento y de expresión. Este derecho comprende la libertad de buscar, recibir y difundir informaciones e ideas de toda índole, sin consideración de fronteras, ya sea oralmente, por escrito o en forma impresa o artística, o por cualquier otro procedimiento de su elección» (Comisión Interamericana de Derechos Humanos, 1969).

Como bien se ha señalado (Loreti, 2014, p. 150), este principio tiene dos aspectos. El primero es el subjetivo, el cual reconoce la universalidad en su titularidad a toda persona. De allí que otros instrumentos del régimen interamericano hayan establecido que «[...] todas las personas deben contar con igualdad de oportunidades para recibir, buscar e impartir información por cualquier medio de comunicación sin discriminación, por ningún motivo, inclusive los de raza, color, religión, sexo, idioma, opiniones políticas o de cualquier otra índole, origen nacional o social, posición económica, nacimiento o cualquier otra condición social» (Comisión Interamericana de Derechos Humanos, 2000, principio 2), así como que «[...] la libertad de expresión requiere que los medios de comunicación social estén virtualmente abiertos a todos sin discriminación, o, más exactamente, que no haya individuos o grupos que, a priori, estén excluidos del acceso a tales medios [...]» (Corte Interamericana de Derechos Humanos, 1985, considerando 34). El segundo es el objetivo, por cuanto dicho derecho debe poder ser ejercido no solo oralmente, por escrito o en forma impresa o artística, sino también por cualquier otro medio de su elección. De allí que la Corte Interamericana haya señalado lo siguiente: «Son los medios de comunicación social los que sirven para materializar el ejercicio de la libertad de expresión, de tal modo que sus condiciones de funcionamiento deben adecuarse a los requerimientos de esa libertad. Para ello es indispensable, inter alia, la pluralidad de medios, la prohibición de todo monopolio respecto de ellos, cualquiera sea la forma que pretenda adoptar $[\ldots] »$ (considerando 34$)$. 
Existe, como se adelantó, una inescindible relación entre el ejercicio del derecho a la libertad de expresión - tanto en su aspecto individual como social (sobre el concepto y las diferencias entre la dimensión individual y social de la libertad de expresión, véase Corte Interamericana de Derechos Humanos, 1985, considerandos 31 y 32) - y la titularidad de los medios a través de los cuales ese derecho puede ser ejercido (Corte Interamericana de Derechos Humanos, 2001). Sin la posibilidad de acceder a un medio de comunicación o de titularizar sobre él algún derecho de propiedad, el derecho a la libertad de expresión sería puramente declarativo.

Ahora bien, esta relación tiene, por su parte, dos correlatos. El primero, que la propiedad de los medios de comunicación, especialmente su concentración, no puede constituirse en un mecanismo para excluir, $a$ priori, a personas o grupos que pretendan dar a conocer sus opiniones (Corte Interamericana de Derechos Humanos, 1985, considerando 34) y, el segundo, que «no se puede restringir el derecho de expresión por vías o medios indirectos, tales como el abuso de controles oficiales o particulares de papel para periódicos, de frecuencias radioeléctricas, o de enseres y aparatos usados en la difusión de información o por cualesquiera otros medios encaminados a impedir la comunicación y la circulación de ideas y opiniones» (Comisión Interamericana de Derechos Humanos, 1969, artículo 13.3.).

Como puede observarse, en el sistema interamericano, el debido ejercicio del derecho a la libertad de expresión impone ciertas restricciones sobre los particulares — sustancialmente, sobre su derecho de propiedad-y sobre los poderes públicos — prohibición de establecer controles oficiales que restrinjan el ejercicio de tal derecho-. Esto hace que, entonces, la regulación de la propiedad de los medios de comunicación sea verdaderamente compleja y delicada por dos motivos. Por un lado, porque la propiedad privada —que también tiene protección convencional en el ámbito interamericano (Comisión Interamericana de Derechos Humanos, 1969, artículo 21) — es, desde el punto de vista económico, «exclusiva y excluyente» (Ogus, 2004, p. 16); por otro lado, porque a la comunicación de ideas e información se le atribuye — como se adelantóel carácter de verdaderos bienes públicos ${ }^{2}$ que, también por definición y como principio, no admiten la exclusión ni por los particulares ni por el Estado (Samuelson \& Nordhaus, 1998, p. 3; sobre la distinción entre bienes privados susceptibles de derecho de propiedad y bienes públicos, desde un punto de vista jurídico económico, véase Sola, 2004, p. 320). Y eso importa el aparente dilema que enfrenta la aplicación del principio de proporcionalidad o razonabilidad en esta materia.

2 Así, se ha señalado que en las sociedades modernas «[...] la información y la comunicación dejan de ser potestades del Estado, de los empresarios periodísticos e, incluso, de los propios periodistas, para convertirse en un derecho humano cuyo titular es el público [...]” (Loreti \& Lozano, 2014, p. 57).

¿REGULAR O

COMPETIR? EL

CASO DE LA LEY

DE SERVICIOS DE

COMUNICACIÓN

AUDIOVISUAL DE

LA REPÚBLICA

ARGENTINA Y EL

PRINCIPIO DE PRO-

PORCIONALIDAD

COMO CRITERIO

DELIMITADOR

¿REGULATION OR

COMPETITION?

THE CASE OF THE

ARGENTINE LAW

OF AUDIOVISUAL

COMMUNICATIONS

SERVICES AND

THE PROPORTIO-

NALITY PRINCIPLE

AS A DELIMITING

CRITERION 


\section{III. ¿POR QUÉ REGULAR LA PROPIEDAD DE LOS MEDIOS DE COMUNICACIÓN? EL CAMBIO DEL PARADIGMA REGULATORIO}

Lacircunstancia de que no exista derechoalgunoque nosea susceptible de ser, en alguna medida, regulado por el Estado (Comisión Interamericana de Derechos Humanos, 1969, artículos 30 y 32.2.) no puede impedir que nos formulemos esta fundamental pregunta. Hemos visto que, en este caso, entran en juegan dos derechos humanos — propiedad y libertad de expresión- que tienen tutela convencional. Dado que toda regulación supone cierta restricción a alguno -0 a ambos- de esos derechos, el interrogante se encuentra plenamente justificado. Toda regulación exige, entonces, una justificación racional.

Tradicionalmente, en el campo de la comunicación, el medio utilizado para comunicar era el criterio sobre cuya base los Estados determinaban la necesidad, o no, de regular la actividad. Así, por razones filosóficas e históricas, por lo general los poderes públicos abdicaban de regular los medios puramente orales, escritos o gráficos ${ }^{3}$, mientras que sí lo hacían cuando los medios eran físicos y de diferente naturaleza, como, por ejemplo, hilos, radioelectricidad, medios ópticos, sistemas electromagnéticos y ondas radioeléctricas. En estos últimos casos, se daba lugar a las regulaciones sobre radiodifusión cuando el medio utilizado eran las ondas radioeléctricas, y a las de telecomunicaciones cuando lo eran los restantes ${ }^{4}$.

En el caso específico de la radiodifusión, amén de otras razones (Loreti, 2014, pp. 164ss.), la principal justificación de la regulación se atribuía al carácter limitado del espectro radioeléctrico, el cual exigía una administración estatal específica a fin de lograr un uso ordenado de las frecuencias y evitar las interferencias, lo que, como principio, se entendió, no constituía una lesión a la libertad de expresión 5 .

3 Se trataba de la llamada libertad de prensa, la cual tiene un especial reconocimiento en la Constitución argentina (artículo 32). Sobre esta cuestión en el derecho argentino, véase el completo tratamiento que ofrece Badeni (2010, pp. 1-319).

4 En este sentido, véase el Convenio Internacional de Telecomunicaciones, celebrado en Nairobi, Kenia (Secretaría General de la Unión Internacional de Telecomunicaciones, 1982), vigente en la República Argentina merced a la ley 23478 (Senado y Cámara de Diputados de la Nación Argentina, 1986). En Argentina, fueron exponentes de esta regulación, hasta tiempos recientes, la Ley Nacional de Telecomunicaciones, número 19798 (Presidencia de la Nación Argentina, 1972) y la Ley de Radiodifusión, número 22285 (Presidencia de la Nación Argentina, 1980). Cabe señalar que, originalmente, la Ley Nacional de Telecomunicaciones incluía la regulación de los servicios de radiodifusión, regulados en ley especial —ley 22285- recién ocho años después. A su vez, mientras que las telecomunicaciones se dirigen a personas determinadas, las emisiones de radiodifusión van hacia el público en general, lo que motivó también una regulación diferenciada; sobre estas cuestiones véase Tau Anzoátegui (2001, p. 1).

5 En su momento, la Corte Suprema de los Estados Unidos de América justificó la regulación de la radiodifusión en el carácter escaso o limitado del espectro radioeléctrico (1943, en especial, el voto del juez Frankfurter; 1969b). Para una crítica sobre este fundamento regulatorio, véase el clásico trabajo de Ronald H. Coase (1988). 
En esta línea, la Corte Suprema argentina tuvo ocasión de señalar que «[...] el derecho a la utilización del espectro de frecuencias radioeléctricas como medio de expresión o comunicación debe ser ejercido conforme a las leyes que lo reglamentan y dentro de los límites que imponga la naturaleza reducida del medio utilizado, los derechos de terceros y el interés público» (Corte Suprema de Justicia de la Nación Argentina, 1999, considerando 9).

Asimismo, y a diferencia de lo que ocurría en otros países, la regulación argentina, aun exigiendo licencia como título habilitante - de las que originalmente solo podían ser titulares sociedades comerciales no controladas por sociedades extranjeras (ley 22285, artículos 45 y 46) ${ }^{6}$ - y el cumplimiento de ciertas obligaciones en la prestación, no calificó a esta actividad como servicio público —a diferencia de lo que ocurrió con las telecomunicaciones (ley 19798, artículos 39ss.) —, sino como una actividad de interés público (ley 22285, artículo 4). A su vez, el carácter limitado del soporte de provisión de servicios también justificó, originalmente, la existencia de ciertas restricciones a la acumulación de licencias por vía de limitaciones impuestas a los socios de las sociedades licenciatarias?

Por otra parte, cabe señalar que el hecho de que una empresa se dedicase a una actividad mediática y que, por ello, su actividad mereciese la protección de la libertad de expresión no impedía que estuviera alcanzada por las normas que rigen la defensa de la competencia en el mercado (Corte Suprema de los Estados Unidos de América, 1945; 1969a). Tampoco podían eludirse de esta sujeción las empresas de radiodifusión por el hecho de tratarse la suya de una actividad de interés público sujeta a especial regulación estatal ${ }^{8}$.

6 La Corte Suprema argentina declaró inconstitucional la restricción al acceso a licencias de radiodifusión por parte de asociaciones civiles o entidades no comerciales (2003).

7 Ley 22285, artículo 45, inciso e, que exigía a los socios de las sociedades licenciatarias «[n] o ser propietario ni socio de diferentes sociedades de radiodifusión. No tener vinculación jurídica o económica con empresas periodísticas extranjeras. Tampoco con empresas periodísticas nacionales», y artículo 46, inciso f: «No podrán transferirse o cederse partes, cuotas o acciones sin autorización del Comité Federal de Radiodifusión o del Poder Ejecutivo Nacional, según lo sea a otros socios o a terceros que reúnan las condiciones y los requisitos previstos por el artículo anterior. En ambos casos, la autorización solo procederá cuando medien causas suficientes para otorgarla, a juicio de la autoridad competente, y siempre que hubiesen transcurrido cinco años contados desde la iniciación de las emisiones regulares. La transgresión a lo establecido en este apartado será considerada falta grave».

8 Esta sujeción de las empresas de radiodifusión al régimen de defensa de la competencia fue expresamente legislada en la Argentina mediante las reformas introducidas en el año 2005 a la Ley 22285 por la ley 26053 (Senado y Cámara de Diputados de la Nación Argentina, 2005). Cabe señalar que la sujeción al régimen de defensa de la competencia por parte de empresas de radiodifusión no se limita al control de las conductas anticompetitivas (control ex post), sino también al régimen de control preventivo o ex ante en casos de operaciones de concentración económica; al respecto, véase la ley argentina de Defensa de la Competencia (Senado y Cámara de Diputados de la Nación Argentina, 1999, ley 25156). Un buen ejemplo de esto lo constituye la resolución $257 / 2007$, dictada por el secretario de Comercio Interior - autoridad de aplicación del régimen de defensa de la competencia argentino-, que aprobó la fusión entre Grupo Clarín y otras empresas y Cablevisión S.A., el principal operador de cable en Argentina. 
Ahora bien, internacionalmente, a partir de la década de 1980, esta visión sobre por qué regular la comunicación comenzó a ser controvertida. Se ha señalado que este cambio de paradigma comenzó en el mismo año 1980 con el informe Un solo mundo, voces múltiples, realizado, por encargo de la UNESCO, por el irlandés Premio Nobel de la Paz Sean MacBride. Dicho informe introdujo por primera vez en el debate internacional las nociones de pluralismo, diversidad, democratización de las comunicaciones, universalidad del derecho a la comunicación y del acceso a la información, temas hasta entonces fuera de la agenda regulatoria. Esta nueva visión - se ha dicho- pretendía contradecir la que hasta el momento se tenía sobre el rol de la actividad comunicacional y de la libertad de prensa como equiparadas a la libertad de empresa así como respecto del rol del Estado, que se entendía como principalmente abstencionista. A partir de ese momento, se inició un movimiento que, pretendiendo dejar atrás ese viejo esquema de regulación, se focalizó en considerar que el rol del Estado radicaba, antes que en intervenir en suplencia de la actividad empresarial o ante razones de índole exclusivamente técnica o económica, en fomentar tales valores: el pluralismo, la diversidad y la democratización de la comunicación (Loreti \& Lozano, pp. 15ss.).

Esta corriente fue encontrando respaldo paulatinamente en el ámbito de protección internacional de los derechos humanos y, en especial, en el ámbito interamericano a partir de 1985 con la ya referida opinión consultiva 5/85 de la Corte Interamericana de Derechos Humanos. Allí, luego de señalarse —como ya vimos-que:

[...] el principio la libertad de expresión requiere que los medios de comunicación social estén virtualmente abiertos a todos sin discriminación, o, más exactamente, que no haya individuos o grupos que, a priori, estén excluidos del acceso a tales medios, exige igualmente ciertas condiciones respecto de estos, de manera que, en la práctica, sean verdaderos instrumentos de esa libertad y no vehículos para restringirla [...] (Corte Interamericana de Derechos Humanos, 1985, considerando 34).

Además, se sostuvo lo siguiente:

Más aún, en los términos amplios de la Convención, la libertad de expresión se puede ver también afectada sin la intervención directa de la acción estatal. Tal supuesto podría llegar a configurarse, por ejemplo, cuando por efecto de la existencia de monopolios u oligopolios en la propiedad de los medios de comunicación, se establecen en la práctica «medios encaminados a impedir la comunicación y la circulación de ideas y opiniones» (considerando 56, las cursivas son mías).

Esta nueva orientación fue fomentada por la Relatoría Especial para la Libertad de Expresión de la Organización de los Estados 
Americanos (OEA). Dicha Relatoría señaló, por un lado, una relación entre el fomento a la libertad de expresión y la lucha contra la pobreza y la exclusión (OEA, 2000) y, por otro, la obligación del Estado de garantizar la pluralidad de voces y de propiedad de los medios de comunicación por cuanto — se entendió- «monopolios y oligopolios conspiran contra la democracia al restringir la pluralidad y diversidad que asegura el pleno ejercicio de la libertad de información de los ciudadanos» (OEA, 2004). En este sentido, también se señaló que muchas veces el derecho de la competencia podía resultar insuficiente para garantizar la pluralidad, razón por la cual se consideró que los Estados podían dictar normas antimonopólicas que garantizasen dicha pluralidad atendiendo a la especial naturaleza de la libertad de expresión (OEA, 2004).

En el ámbito académico, el profesor de la Yale Law School, Owen Fiss, ha sintetizado con claridad lo que esta nueva visión ampara: «El Estado puede verse obligado a actuar para promover el debate público: cuando poderes de carácter no estatal ahogan la expresión de opiniones [...] Puede que el Estado tenga, incluso, que silenciar voces de algunos para que se oigan las voces de los demás; a veces, no hay más remedio [...]» $(1999$, p. 14). En definitiva, fluye aquí la idea de que (a) la información y la comunicación son bienes públicos que no admiten la exclusión; (b) la propiedad de medios, especialmente la concentrada, puede ser un instrumento para excluir a personas y grupos del acceso a su derecho a comunicar e informar; (c) la pluralidad y diversidad de medios promueve la pluralidad y diversidad de voces y es, por ello, un reaseguro de los valores democráticos; (d) las regulaciones de tipo meramente técnico y económico pueden ser insuficientes para promover dicha pluralidad y diversidad considerando el carácter no económico que tienen los derechos a la información, libre expresión y comunicación; (e) el Estado no garantiza el derecho a la libertad de expresión con su intervención minimalista o abstencionista, sino que debe fomentar, de modo activo y a través de sus regulaciones o limitaciones sobre la propiedad de los medios, tales requisitos de pluralidad y diversidad (para un análisis detallado - y favorable- de esta visión, véase Loreti \& Lozano, 2014, pp. 46-67).

En la Argentina, este nuevo paradigma de regulación comenzó a desarrollarse a comienzos del siglo XXI, especialmente a partir del año 2004, gracias al impulso de la llamada Coalición por una Radiodifusión Democrática, constituida con el fin primordial de reemplazar la ley 22285, sancionada en 1980 por el gobierno militar?. Según dicha

9 La Coalición por una Radiodifusión Democrática es un grupo de sindicatos de prensa, universidades, organizaciones sociales, radios comunitarias, pequeñas radios comerciales y organismos de derechos humanos, entre otros, convocado en 2004 por el Foro Argentino de Radios Comunitarias y que ha presentado 21 puntos básicos para una nueva ley de radiodifusión que remplazase a la ley 22285, dictada en 1980 por el gobierno militar.

¿REGULAR O

COMPETIR? EL

CASO DE LA LEY

DE SERVICIOS DE

COMUNICACIÓN

AUDIOVISUAL DE

LA REPÚBLICA

ARGENTINA Y EL

PRINCIPIO DE PRO-

PORCIONALIDAD

COMO CRITERIO

DELIMITADOR

¿REGULATION OR

COMPETITION?

THE CASE OF THE

ARGENTINE LAW

OF AUDIOVISUAL

COMMUNICATIONS

SERVICES AND

THE PROPORTIO-

NALITY PRINCIPLE

AS A DELIMITING

CRITERION 
organización, entre otras afirmaciones de principios, la radiodifusión es una forma de ejercicio del derecho a la información y a la cultura y no un simple negocio comercial, de allí que la regulación de los medios de radiodifusión debía tener como objetivo primordial promover la diversidad y el pluralismo, garantizándose el acceso de todos los sectores de la sociedad a la titularidad y la gestión de los servicios. Asimismo, la ley debía impedir la formación de monopolios y oligopolios en el sector, a los que consideraba como conspiradores contra la democracia (Coalición por una Radiodifusión Democrática, s/f).

Lo cierto es que el cambio normativo tuvo lugar como consecuencia de la llamada crisis del campo, del año 2008 —vinculada con la imposición de retenciones móviles a los ingresos provenientes de la exportación de productos agropecuarios-, cuando el principal grupo multimedios del país, el Grupo Clarín, tomó clara posición a favor de los reclamos del sector ruralista y contra los intereses del Gobierno nacional ${ }^{10}$. En ese contexto, la entonces presidente de la Nación presentó, en marzo de 2009, el proyecto de Ley de Servicios de Comunicación Audiovisual - en el que se adoptó gran parte de los principios propugnados por la Coalición por una Radiodifusión Democrática一, el cual, luego de un amplio debate durante siete meses, tanto en sede parlamentaria como en el marco de la sociedad civil y empresaria y de índole más política que técnica, fue - en una situación poco común - sancionado por el Congreso Nacional, promulgado como ley por el Poder Ejecutivo y publicado en el Boletín Oficial en un mismo día, el 10 de octubre de 2009.

La LSCA, amén de continuar con la tradición normativa argentina de no regular la comunicación a través de medios gráficos ${ }^{11}$, pero partiendo del principio que reza que «contenidos audiovisuales idénticos o similares deben ser reglamentados por el mismo marco regulatorio, independientemente de la tecnología de transmisión», señaló lo siguiente:

[...] el destino de la presente ley atiende a la previsión legal de los servicios de comunicación audiovisual como una realidad más abarcativa que la restringida emergente del concepto de radiodifusión, toda vez que las tendencias legiferantes en el conjunto de los países no solo se dedican a contemplar a las instancias destinadas a las condiciones de los medios en tanto emisores últimos frente al público, sino también

10 Que la "crisis del campo" y los conflictos generados a su amparo fueron el detonante de la reforma legislativa es reconocido aun por quienes son firmes partidarios de la bondad de esta última, véase Loreti \& Lozano (2014, pp. 185-186).

11 No obstante, cabe destacar que la ley 26736 declaró de «interés público la fabricación, comercialización y distribución de pasta celulosa y de papel para diarios", sometiendo el acceso a dichos insumos a una detallada regulación con características de un régimen de «facilidades esenciales» (Senado y Cámara de Diputados de la Nación Argentina, 2011). 
otras circunstancias de orden de políticas públicas regulatorias y de promoción del derecho a la información y al aprovechamiento y alfabetización tecnológica superando los criterios basados en la sola previsión del soporte técnico (LSCA, nota al artículo 1).

De allí que la norma se refiera a su objeto propio de regulación, es decir, a la «comunicación audiovisual» como:

[...] la actividad cultural cuya responsabilidad editorial corresponde a un prestador de un servicio de comunicación audiovisual, o productor de señales o contenidos cuya finalidad es proporcionar programas o contenidos, sobre la base de un horario de programación, con el objeto de informar, entretener o educar al público en general a través de redes de comunicación electrónicas. Comprende la radiodifusión televisiva, hacia receptores fijos, hacia receptores móviles así, como también servicios de radiodifusión sonora, independientemente del soporte utilizado, o por servicio satelital; con o sin suscripción en cualquiera de los casos (artículo 4).

Como se puede observar, el carácter limitado del espectro radioeléctrico — si bien siguió justificando la regulación de la actividad cuando se la presta con soporte en este medio (artículo 7) — no constituyó ya el fundamento exclusivo de la regulación de la radiodifusión. Se comprendió también los servicios prestados con apoyo en otros medios diferentes de aquel como, por ejemplo, el cable y las facilidades satelitales ${ }^{12}$.

Aun cuando se continuó con la tradición argentina de calificar a la actividad como una «de interés público» y no como un servicio público (artículo 2), el impacto novedoso de la LSCA se advierte, claramente, ya en el objetivo de la regulación, a saber, «[...] el desarrollo de mecanismos destinados a la promoción, desconcentración y fomento de la competencia con fines de abaratamiento, democratización y universalización del aprovechamiento de las nuevas tecnologías de la información y la comunicación» (artículo 1), así como que «[...] el objeto primordial de la actividad brindada por los servicios regulados [...] es la promoción de la diversidad y la universalidad en el acceso y la participación, implicando ello igualdad de oportunidades de todos los habitantes de la Nación para acceder a los beneficios de su prestación $[\ldots] »($ artículo 2$)$.

Más allá del amplio contenido regulatorio de la LSCA, para este trabajo solo nos interesa destacar las limitaciones de naturaleza antitrust per se y de tipo sectorial que la norma introdujo a fin de garantizar los apuntados objetivos y que, en lo sustancial y salvo las que señalamos en el apartado $b$

¿REGULAR O

COMPETIR? EL

CASO DE LA LEY

DE SERVICIOS DE

COMUNICACIÓN

AUDIOVISUAL DE

LA REPÚBLICA

ARGENTINA Y EL

PRINCIPIO DE PRO-

PORCIONALIDAD

COMO CRITERIO

DELIMITADOR

¿REGULATION OR

COMPETITION?

THE CASE OF THE

ARGENTINE LAW

OF AUDIOVISUAL

COMMUNICATIONS

SERVICES AND

THE PROPORTIO-

NALITY PRINCIPLE

AS A DELIMITING

CRITERION 
que sigue, fueron las que cuestionó judicialmente el Grupo Clarín ante la justicia (Bianchi \& Sacristán, 2014, en especial p.2). Así, podemos destacar las siguientes limitaciones ${ }^{13}$ :

a. Restricciones a la cantidad máxima de licencias de las que puede ser titular una persona de existencia visible o ideal o bien tener participación en sociedades titulares de licencias de servicios de radiodifusión ${ }^{14}$.

b. Restricciones a la posibilidad de acumular — por parte de empresas que presten servicios de radiodifusión por cable o móvil- licencias de otros servicios propios de distinta clase o naturaleza ${ }^{15}$.

13 Cabe señalar que el Decreto 267/2015 introdujo importantes modificaciones en estas regulaciones.

14 LSCA, artículo 45: «Multiplicidad de licencias. A fin de garantizar los principios de diversidad, pluralidad y respeto por lo local se establecen limitaciones a la concentración de licencias.

En tal sentido, una persona de existencia visible o ideal podrá ser titular o tener participación en sociedades titulares de licencias de servicios de radiodifusión, sujeto a los siguientes límites:

1. En el orden nacional:

a) Una (1) licencia de servicios de comunicación audiovisual sobre soporte satelital. La titularidad de una licencia de servicios de comunicación audiovisual satelital por suscripción excluye la posibilidad de ser titular de cualquier otro tipo de licencias de servicios de comunicación audiovisual;

b) Hasta diez (10) licencias de servicios de comunicación audiovisual más la titularidad del registro de una señal de contenidos, cuando se trate de servicios de radiodifusión sonora, de radiodifusión televisiva abierta y de radiodifusión televisiva por suscripción con uso de espectro radioeléctrico;

c) Hasta veinticuatro (24) licencias, sin perjuicio de las obligaciones emergentes de cada licencia otorgada, cuando se trate de licencias para la explotación de servicios de radiodifusión por suscripción con vínculo físico en diferentes localizaciones. La autoridad de aplicación determinará los alcances territoriales y de población de las licencias.

La multiplicidad de licencias - a nivel nacional y para todos los servicios—en ningún caso podrá implicar la posibilidad de prestar servicios a más del treinta y cinco por ciento $(35 \%)$ del total nacional de habitantes o de abonados a los servicios referidos en este artículo, según corresponda.

2. En el orden local:

a) Hasta una (1) licencia de radiodifusión sonora por modulación de amplitud (AM);

b) Una (1) licencia de radiodifusión sonora por modulación de frecuencia (FM) o hasta dos (2) licencias cuando existan más de ocho (8) licencias en el área primaria de servicio;

c) Hasta una (1) licencia de radiodifusión televisiva por suscripción, siempre que el solicitante no fuera titular de una licencia de televisión abierta;

d) Hasta una (1) licencia de radiodifusión televisiva abierta siempre que el solicitante no fuera titular de una licencia de televisión por suscripción;

En ningún caso la suma del total de licencias otorgadas en la misma área primaria de servicio o conjunto de ellas que se superpongan de modo mayoritario, podrá exceder la cantidad de tres (3) licencias.

3. Señales:

La titularidad de registros de señales deberá ajustarse a las siguientes reglas:

a) Para los prestadores consignados en el apartado 1, subapartado "b", se permitirá la titularidad del registro de una (1) señal de servicios audiovisuales;

b) Los prestadores de servicios de televisión por suscripción no podrán ser titulares de registro de señales, con excepción de la señal de generación propia.

Cuando el titular de un servicio solicite la adjudicación de otra licencia en la misma área o en un área adyacente con amplia superposición, no podrá otorgarse cuando el servicio solicitado utilice la única frecuencia disponible en dicha zona».

15 LSCA, artículo 46: «No concurrencia. Las licencias de servicios de radiodifusión directa por satélite y las licencias de servicios de radiodifusión móvil tendrán como condición de otorgamiento y continuidad de su vigencia - cada una de ellas - que no podrán ser acumuladas con licencias de otros servicios propios de distinta clase o naturaleza, salvo para la transmisión del servicio de televisión terrestre abierta existente en forma previa a los procesos de transición a los servicios digitalizados y el canal que lo reemplace oportunamente». 
c. Necesidad de controlar, por parte de la autoridad de aplicación, de modo previo al otorgamiento de licencias o a la autorización para ceder acciones o cuotas partes, la existencia de vínculos societarios que exhiban procesos de concentración vertical u horizontal de actividades ligadas o no a la comunicación social, así como la imposibilidad de alegar derechos adquiridos emergentes del régimen de multiplicidad de licencias frente a normas generales de desmonopolización o defensa de la competencia ${ }^{16}$.

d. La obligación de desinversión en caso de que no se cumpla con las limitaciones impuestas por la LSCA como modo de adecuación a las nuevas restricciones ${ }^{17}$.

En definitiva, la LSCA muestra con claridad el cambio del paradigma regulatorio en esta materia y, paralelamente, la introducción de restricciones ex ante de índole antitrust sectorial a la propiedad de licencias o medios de comunicación con la finalidad de promover la desconcentración, el pluralismo informativo y el acceso a tales medios.

\section{LA REGULACION DE LA PROPIEDAD DE LOS MEDIOS DE COMUNICACIÓN Y EL PRINCIPIO DE ADECUACIÓN}

Como es sabido, el término razonabilidad también puede ser vinculado con la idea de adecuación entre medios y fines (Bazán \& Madrid, 1991, p. 181). En Argentina se ha dicho que «lo razonable es lo proporcionado al efecto, lo exigido por la igualdad y la equidad, lo armónico dentro del todo, lo equilibrado entre los extremos» (Haro, 2003, p. 201). En un sentido jurídico amplio, la proporcionalidad implica que toda intervención pública sobre las actividades de los ciudadanos, para ser válida, debe ser idónea, indispensable y proporcionada en sentido estricto (Cianciardo, 2009, p. 27).

16 LSCA, artículo 48: «Prácticas de concentración indebida. Previo a la adjudicación de licencias o a la autorización para la cesión de acciones o cuotas partes, se deberá verificar la existencia de vínculos societarios que exhiban procesos de integración vertical u horizontal de actividades ligadas, o no, a la comunicación social.

El régimen de multiplicidad de licencias previsto en esta ley no podrá alegarse como derecho adquirido frente a las normas generales que, en materia de desregulación, desmonopolización o defensa de la competencia, se establezcan por la presente o en el futuro.

Se considera incompatible la titularidad de licencias de distintas clases de servicios entre sí cuando no den cumplimiento a los límites establecidos en los artículos 45, 46 y concordantes».

17 LSCA, artículo 161: «Adecuación. Los titulares de licencias de los servicios y registros regulados por esta ley, que a la fecha de su sanción no reúnan o no cumplan los requisitos previstos por la misma, o las personas jurídicas que al momento de entrada en vigencia de esta ley fueran titulares de una cantidad mayor de licencias, o con una composición societaria diferente a la permitida, deberán ajustarse a las disposiciones de la presente en un plazo no mayor a un (1) año desde que la autoridad de aplicación establezca los mecanismos de transición. Vencido dicho plazo, serán aplicables las medidas que al incumplimiento - en cada caso - correspondiesen.

Al solo efecto de la adecuación prevista en este artículo, se permitirá la transferencia de licencias. Será aplicable lo dispuesto por el último párrafo del artículo 41 ». 
En este contexto, entonces, el subprincipio de adecuación supone evaluar si la medida dictada por el Estado es capaz de causar la finalidad que dice perseguir. Dicho en otros términos, supone un juicio de idoneidad acerca de la medida enjuiciada en función del fin establecido por la norma (Cianciardo, 2009, p. 64), o bien un juicio de eficacia de esta, entendiendo que una decisión es eficaz cuando sirve al propósito para el cual estaba prevista (Sacristán, 2005, p. 113). Acertadamente, autores argentinos como Linares (1989, p. 138), Bidart Campos (1968, p. 238), Padilla (1984, p.1107) y Bianchi (1991, p. 170), entre otros (Kaufman, 1991, p. 678; Grondona, 1986, pp. 174ss.; 2004), señalaron la imposibilidad de observar qué razonabilidad o proporcionalidad entre medios y fines podía determinarse si no se lleva a cabo un análisis, en primer término, de la idoneidad técnica del medio empleado para la consecución del fin. Cabe señalar que este test de adecuación es de naturaleza exclusivamente bilateral, es decir, solo analiza la idoneidad del medio empleado frente al fin perseguido, pero no hace un análisis comparativo con otros medios, también adecuados, pero no elegidos por la autoridad. Ello es objeto de otro subprincipio, el de necesidad (Cianciardo, 2009, p. 95). De todas formas, el subprincipio de adecuación tiene sus limitaciones, puesto que se considera que el control lo cumplimenta al comprobar que la medida adoptada es susceptible de lograr, aun en forma parcial, la finalidad perseguida (Cianciardo, 2009, p. 78; por otra parte, se ha señalado que la jurisprudencia europea solo exige que el medio elegido no sea manifiestamente inadecuado para el logro de la finalidad perseguida, Schwarze, 1992, p. 856).

Ahora bien, en el caso que nos ocupa, la pregunta que debemos formularnos es la siguiente: ilas medidas restrictivas sobre la propiedad de medios y licencias contenidas en la LSCA son técnicamente adecuadas al logro de los fines que la ley persigue (verbigracia, pluralidad de prestadores y de voces)? Para la mayoría de los jueces de la Corte Suprema que resolvieron el caso Grupo Clarín, la respuesta fue afirmativa. Al respecto, los jueces Lorenzetti y Highton de Nolasco señalaron en cuanto al régimen de multiplicidad de licencias que:

[...] no se requiere un mayor esfuerzo expositivo para concluir que las medidas en cuestión resultan idóneas para cumplir con los objetivos mencionados, en tanto las restricciones contenidas en el artículo 45 a la cantidad de licencias y registros aparecen como apropiadas o aptas para permitir la participación de un mayor número de voces, o al menos poseen entidad suficiente como para contribuir de algún modo a ese objetivo. Es evidente que a través de la limitación de la cantidad de licencias y registros a todos los operadores de medios de comunicación se podría evitar la concentración y ello permitiría una mayor participación y diversidad de opiniones (Corte Suprema de Justicia de la Nación Argentina, 2013, considerando 43 de su voto conjunto). 
A similar conclusión arribaron —con la excepción del juez Fayt— los restantes miembros del tribunal, aunque con argumentos diferenciados (para un análisis particular de los restantes votos, véase Bianchi \& Sacristán, 2014).

Por nuestra parte, consideramos que el razonamiento utilizado no se hace cargo de las siguientes cuestiones: En primer lugar, entendemos que, si bien es posible que la concentración pueda afectar la pluralidad de voces, la pluralidad de prestadores no supone necesariamente una verdadera pluralidad de voces (Becerra, 2015, p. 81) ${ }^{18}$, puesto que ello depende de circunstancias particulares. Así, bien puede ocurrir que, por un lado, no exista un procedimiento equitativo y transparente en la adjudicación de licencias que efectivamente fomente la diversidad y pluralidad y, por otro lado, que un conglomerado de empresas de poca escala económica, para poder actuar, deba depender - como ocurre en Argentina y en varios países de nuestra región- de la asignación de la pauta publicitaria oficial, con lo cual la simple pluralidad de operadores de modo alguno garantiza, per se, la pretendida pluralidad de voces (Becerra, 2015, pp. 107ss.). Por ello, tampoco resulta decisivo el hecho de que en otros países - con marcos institucionales, prácticas políticas y mercados diferentes de los nuestros- modernamente las regulaciones hayan recurrido a medidas que guardan cierta analogía con las aquí comentadas para intentar promover la diversidad de opiniones (pp. 77ss.).

En segundo lugar, no podemos olvidar que - aun bajo la nueva visión que hoy se propugna - el derecho a la libertad de expresión e información sigue manteniendo su rol de control del poder político - también concentrado- Caben, al respecto, las consideraciones que en su momento formuló Tocqueville, en el sentido de que una asociación industrial y comercial robusta «es un ciudadano ilustrado y poderoso que no se puede sujetar a voluntad ni oprimir en las tinieblas y que, al defender sus derechos particulares contra las exigencias del poder, salva las libertades comunes» $(1996$, p. 637). Una empresa de comunicación que por su tamaño y escala puede desarrollarse sin depender de los favores estatales es una empresa que cuenta con «espaldas» suficientes para controlar al poder político. Ello no significa, de modo alguno, que tales empresas no puedan abusar de su posición de dominio ni que deban quedar exentas de todo control estatal. Se trata de que la empresa de envergadura puede evitar los peligros que se derivan de la atomización del sector en pequeñas empresas que carecen de la suficiente aptitud económica para oponerse a los caprichos del gobierno. El «poder de

¿REGULAR O

COMPETIR? EL

CASO DE LA LEY

DE SERVICIOS DE

COMUNICACIÓN

AUDIOVISUAL DE

LA REPÚBLICA

ARGENTINA Y EL

PRINCIPIO DE PRO-

PORCIONALIDAD

COMO CRITERIO

DELIMITADOR

¿REGULATION OR

COMPETITION?

THE CASE OF THE

ARGENTINE LAW

OF AUDIOVISUAL

COMMUNICATIONS

SERVICES AND

THE PROPORTIO-

NALITY PRINCIPLE

AS A DELIMITING

CRITERION 
mercado» tiene, así y en este campo, una clara implicancia política e institucional.

En tercer lugar, y estrechamente vinculado con lo anterior, la industria de medios exige cierta escala para ser competitiva y para poder innovar (sobre la cuestión de la concentración en el sector y cómo debe medírsela, véase Becerra, 2015, pp. 59 y 81). Así, una desmonopolización que derive en límites al poder de mercado o a la tenencia de licencias múltiples, aun cuando ello no torne completamente inviable la capacidad de actuación de la empresa, puede llevar a que, en lugar de fomentar el ingreso de nuevos prestadores, en realidad se lo restrinja. En otros términos, no cabe descartar a priori que una limitación a la propiedad de licencias y empresas de medios derive en el establecimiento de una barrera de entrada para nuevos operadores, algo completamente contrario a lo que, en teoría, se perseguiría con esta clase de regulaciones directas ${ }^{19}$.

En cuarto lugar, si bien es adecuado a la finalidad perseguida que si la prestación se realiza con apoyo en un bien limitado, como es el espectro radioeléctrico, se impongan límites estructurales a la multiplicidad de licencias o a las tenencias cruzadas, no se sigue que, cuando no se utiliza espectro radioeléctrico, tales limitaciones también resulten adecuadas a dichas finalidades. Como lo sostuvo uno de los jueces de la Cámara Federal de Apelaciones en lo Civil y Comercial que entendió en segunda instancia en el caso Grupo Clarín:

La TV por cable no utiliza espectro radioeléctrico y por lo tanto no hay fundamento económico o de defensa de la competencia que justifique la restricción [...] Los argumentos de la asignación de un recurso escaso como es el espectro no son aplicables a la televisión por cable porque no hay ningún recurso escaso que deba distribuirse equitativamente ${ }^{20}$.

En definitiva, y más allá de las particulares circunstancias del caso Grupo Clarín, subsisten dudas más que razonables acerca de si las medidas que llevan per se a la limitación a la propiedad de medios de comunicación, especialmente cuando la prestación de servicios no se apoya en la utilización del espectro radioeléctrico, son mecanismos idóneos para garantizar la pluralidad y diversidad informativa y de ideas que se pretende con la regulación.

19 Según surge del fallo de segunda instancia en el caso Grupo Clarín, la pericia contable había dado cuenta de que, como fruto de la aplicación de las medidas impugnadas, la pérdida de economías de escala colocaba a la empresa en una situación de desventaja competitiva frente a la televisión satelital y, asimismo, incrementaba los costos de los servicios a ser prestados al público.

20 Cámara Nacional de Apelaciones en lo Civil y Comercial Federal, Sala I, Grupo Clarín S.A. y otros, fallo del 17 de abril de 2013, voto del juez Guarinoni, considerando 8; en similar sentido, véase el voto del juez Fayt en el fallo de la Corte Suprema (2013, considerando 29). 


\section{V.LA REGULACIÓN DE LA PROPIEDAD DE LOS MEDIOS} DE COMUNICACIÓN Y EL PRINCIPIO DE NECESIDAD El subprincipio de necesidad supone examinar si la medida adoptada por la autoridad es la menos restrictiva de los derechos del particular de entre otras igualmente eficaces. Exige, en definitiva, analizar si el medio escogido constituye el menos gravoso respecto del derecho afectado (Cianciardo, 2009, pp. 82-83) o, dicho de otra forma, verificar si la medida escogida se limita o no a restringir el derecho a lo necesario para el logro de la finalidad perseguida (Blanke, 2009, p. 606). Consiste, a diferencia del juicio de «idoneidad» —que se basa en una determinación bilateral exclusiva de medios a fines-, en un análisis plurilateral, vertical y horizontal simultáneamente, entre el medio escogido, el fin buscado y otros medios hipotéticos, de modo tal que, primero, se compara cada medio posible con el fin y, después, se lleva a cabo una comparación del medio escogido y los medios alternativos no escogidos por la autoridad (Cianciardo, 2009, p. 95).

Este juicio tiene suma relevancia al momento de juzgar acerca de medidas de intervención sobre los derechos de propiedad, puesto que afectar recursos de los particulares más allá de lo necesario para lograr la finalidad perseguida comporta, desde el exclusivo punto de vista económico, una solución ineficiente o, lisa y llanamente, la destrucción de bienes escasos o de riqueza ${ }^{21}$. Es que, en rigor, el juicio de necesidad supone un juicio de eficiencia (Cianciardo, 2009, p. 95). En este sentido, debe tenerse presente que no cabe considerar superfluos a los recursos necesarios para invertir y llevar adelante negocios y empresas que contribuyen al desarrollo del bienestar general (Finnis, 1998, p. 194). Como se puede observar, el subprincipio de necesidad traduce, en términos jurídicos, la aplicación del principio de subsidiariedad, el cual, consagrado por la doctrina social de la Iglesia, constituye un límite demarcador de las competencias entre las sociedades civiles y particulares y el Estado (Sánchez Agesta, 1986, p. 69). En esta línea, cabe señalar que la Corte Interamericana de Derechos Humanos ha dicho que «[l]a Corte considera que a fin de que el Estado pueda satisfacer legítimamente un interés social y encontrar un justo equilibrio con el interés del particular, debe utilizar los medios proporcionales a fin de vulnerar en la menor medida el derecho a la propiedad de la persona objeto de la restricción» (2008, número 63; 2012, número 222; entre otros).

Abdicar de un control sobre la necesidad de la medida de intervención adoptada por la autoridad deriva en que, necesariamente, no se pueda verificar si, por ejemplo, las finalidades que animan una determinada

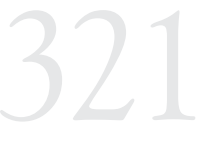

¿REGULAR O

COMPETIR? EL

CASO DE LA LEY

DE SERVICIOS DE

COMUNICACIÓN

AUDIOVISUAL DE

LA REPÚBLICA

ARGENTINA Y EL

PRINCIPIO DE PRO-

PORCIONALIDAD

COMO CRITERIO

DELIMITADOR

¿REGULATION OR

COMPETITION?

THE CASE OF THE

ARGENTINE LAW

OF AUDIOVISUAL

COMMUNICATIONS

SERVICES AND

THE PROPORTIO-

NALITY PRINCIPLE

AS A DELIMITING

CRITERION

21 De allí que Alexy haya sostenido que «el subprincipio de necesidad también es una expresión de la idea de "óptimo de Pareto". A causa de la existencia de un medio más benigno e igualmente idóneo, puede mejorarse una posición sin que esto represente costes para la otra» (2002, p. 29; véase también 2005, en especial p. 573; Grondona, 1986, p. 174). 
regulación pueden ser logradas por un medio de intervención menos restrictivo para los derechos de los agentes económicos, como lo puede ser, por ejemplo, la aplicación del régimen de defensa de la competencia o cualquier otro de los llamados instrumentos de light-handed regulation, aspecto este de relevancia en la temática que analizamos, tal como veremos seguidamente.

En definitiva, omitir el subprincipio de necesidad en esta materia termina habilitando a los reguladores a que consideren que se encuentran habilitados para regular — y aun para hacerlo con cualquier intensidadcualquier industria con tal de que se invoquen fines plausibles. Así, solamente quedan a salvo aquellos supuestos excepcionales en los que la regulación importe la completa confiscación de activos y derechos de los operadores económicos, circunstancia esta que solo puede constituir un límite extremo y, por lo tanto, ineficaz para pautar los principios que deben regir una buena regulación.

Pues bien, en el tema que analizamos, la pregunta que debemos formularnos es la siguiente: Asumiendo la adecuación de las medidas restrictivas de la propiedad de licencias y medios de comunicación, itales medidas de regulación general, ex ante y directa, son necesarias para el logro de tales fines o estos podrían lograrse a través de medidas menos restrictivas como, por ejemplo, el control caso por caso, tanto ex ante como ex post, a través del régimen general de defensa de la competencia? Téngase presente que regulaciones como la contenida en la LSCA suponen una regulación antitrust per se, o sea, que el legislador, de antemano, ha juzgado que ante determinado nivel de concentración de propiedad en el sector se afectan los fines perseguidos de garantizar una real pluralidad de voces y de contenidos informativos.

En el caso del Grupo Clarín, la mayoría de la Corte argentina — siguiendo en esto su tradicional jurisprudencia—, reflejada en el voto de los jueces Lorenzetti y Highton de Nolasco, omitió efectuar este control por cuanto consideró que analizar si la medida adoptada por el legislador era o no la menos restrictiva importaba tanto como pronunciarse sobre su oportunidad, mérito y la conveniencia, lo que se encuentra vedado a la judicatura por imperio del principio de separación de poderes. Por otro lado, asumiendo que se trataba de analizar una restricción sobre el derecho de propiedad $-\mathrm{y}$ no sobre una libertad de las llamadas ideológicas, como la libertad de expresión-, no cabía - se dijo- un escrutinio estricto, sino uno deferente (Corte Suprema de Justicia de la Nación Argentina, 2013, considerandos 38, 50 y 51 del voto conjunto). Por lo contrario, el juez Petracchi sí entró a considerar el requisito de necesidad, a cuyo respecto sostuvo lo siguiente:

Que la necesidad de tales medidas también se encuentra justificada por la especificidad de los bienes jurídicos protegidos y la insuficiencia de las 
normas generales de defensa de la competencia para lograr los objetivos de pluralismo y diversidad a los que se hizo referencia. En efecto, la concepción según la cual los medios reducen su significación a meros objetos económicos, sujetos a las reglas de la libertad de comercio, ha quedado desplazada. Al afirmarse como bienes valiosos para la preservación de identidades culturales diversas y como garantes del pluralismo, queda planteada la tensión entre la libertad comercial y la necesidad de asegurar una libertad de expresión amplia, plural y diversa. Desde esta perspectiva, las reglas destinadas a regular la defensa de la competencia no resultan suficientes, por cuanto ellas intervienen frente al monopolio o «posición dominante» únicamente como fenómenos distorsivos del mercado y de la libertad empresaria. En cambio, lo que en el caso se encuentra en juego es fomentar una oferta plural y diversa y, fundamentalmente, evitar una formación homogeneizada de la opinión pública. En otras palabras, cuando la concentración empresarial supera ciertos límites, puede afectar la efectiva libertad de comercio, por dominio del mercado. Pero cuando la concentración se produce en el «mercado de la información», ella puede restringir la libertad de expresión y el derecho a la información de la sociedad (considerando 24 de su voto).

Desde nuestra perspectiva, cabe formular las siguientes consideraciones: En primer lugar, la circunstancia de que el régimen de defensa de la competencia actúe sobre fines y realidades económicos, mientras que en materia de libertad de expresión estemos ante una realidad cultural, pretensamente no subsumible bajo cánones mercantiles o empresariales, no parece ser una respuesta adecuada ante el subprincipio de necesidad. Como lo anticipamos, la verdadera pregunta que debemos hacernos es si la aplicación del régimen de defensa de competencia - menos restrictiva que la regulación directa sectorial, per se y ex ante - puede conducir, de presentarse un supuesto de abuso de posición de dominio, con menor sacrificio de derechos, a idénticos fines y objetivos. Y lo cierto es que, sobre el particular, no se respondió a esta cuestión. Téngase presente, al respecto, que el ejercicio del poder de mercado depende de la coyuntura y de múltiples variables que pueden mutar con el tiempo y con la evolución de los mercados y de las tecnologías. Así, debería existir una justificación racional muy fuerte para abandonar un control «horizontal» y caso por caso - propio del régimen de defensa de la competencia- a favor de uno general, per se, ex ante y de tipo exclusivamente sectorial.

En segundo lugar, no cabe omitir en esta clase de análisis que — como bien se ha dicho- los mercados que tienden a la concentración por sus exigencias de producción, por sus costos de entrada y operación, como los medios masivos de comunicación en procesos de convergencia, pueden aspirar a desarrollar «competencias moderadas» en pos de alentar la diversidad, mientras que su atomización conduciría a la

¿REGULAR O

COMPETIR? EL

CASO DE LA LEY

DE SERVICIOS DE

COMUNICACIÓN

AUDIOVISUAL DE

LA REPÚBLICA

ARGENTINA Y EL

PRINCIPIO DE PRO-

PORCIONALIDAD

COMO CRITERIO

DELIMITADOR

¿REGULATION OR

COMPETITION?

THE CASE OF THE

ARGENTINE LAW

OF AUDIOVISUAL

COMMUNICATIONS

SERVICES AND

THE PROPORTIO-

NALITY PRINCIPLE

AS A DELIMITING

CRITERION 
«competencia ruinosa» que destruiría su base misma de funcionamiento (Becerra, 2015, p. 81). Esto resultaría demostrativo de que, en mercados como el audiovisual, la concentración empresaria no llevaría, por sí misma, a limitar la diversidad y la competencia como lo presumiría — sin admitir prueba en contra - la regulación directa y sectorial, sino todo lo contrario, puesto que garantizaría la vigencia de esos valores. Así, en este caso, y paradójicamente, la regulación suprimiría la competencia posible en el sector, lo que constituye un verdadero contrasentido ${ }^{22}$. Téngase en cuenta que, como bien se ha señalado, la competencia posible es siempre una alternativa más eficiente que la regulación estatal directa y, por lo tanto, preferible (véase, por ejemplo, Baldwin \& Cave, 1999, pp. 210-223; Grenfell, 1999, pp. 221-234; Vickers, 1996, pp. 91-105; Stelzer, 2002; Littlechild, 2002; Breyer, 1982, pp. 185-186, entre muchos otros).

En tercer lugar, efectuar esa distinción entre derecho de propiedad y realidades empresariales, por un lado, y, por otro lado, la promoción de «algo distinto» como la libertad de expresión es, lisa y llanamente, erróneo. Ya hemos visto cómo, incluso en el sistema interamericano, no queda duda de que existe una relación inescindible entre libertad de expresión y propiedad de los medios de comunicación, y cómo restringir la propiedad de medios o abusar de ella puede afectar —en uno y otro caso- el ejercicio y la plenitud del derecho de libertad de expresión. Así, sin plenos derechos de propiedad sobre los medios, no hay libertad de expresión posible, porque este último derecho —en el mundo moderno- se ejerce necesariamente a través de la propiedad de medios de comunicación.

En cuarto lugar, también aquí entra a tallar la diferenciación entre servicios prestados con asiento en espectro radioeléctrico y aquellos otros prestados con apoyo en soportes diferentes. ¿Qué es lo que justifica en estos últimos casos, cuando no existe limitación técnica alguna en el soporte, recurrir a un gravoso remedio como la división o limitación de la propiedad? (Corte Suprema de Justicia de la Nación Argentina, 2013, voto del juez Fayt, considerando 29). Se corre aquí el riesgo de revestir, con la forma de una regulación sectorial y antimonopólica per se, una intención de restringir la libertad de expresión ${ }^{23}$.

22 Se ha dicho que «[l]a necesidad de regulación no significa que haya que suprimir la competencia. Se pueden corregir los problemas del mercado manteniendo la competencia, porque el problema está en el mercado y no en la competencia. Que existan fallos del mercado no significa que haya fallos de la competencia» (Fernández Ordóñez, 2000, p. 65). Análogamente, ha dicho Ariño Ortiz que "[e]n el difícil equilibrio entre mercado y regulación, la competencia es el objetivo prioritario y la regulación es el instrumento necesario para defender la competencia (para crearla cuando aquélla no existe) o para sustituirla cuando sea imposible su creación porque existan elementos de monopolio natural» (2012, p. 114).

23 Al respecto, téngase presente que en su informe del año 2004, la Relatoría para la Libertad de Expresión de la OEA señaló lo siguiente: «La Relatoría considera que el marco del derecho de la competencia en muchas ocasiones puede resultar insuficiente, particularmente en cuanto a la asignación de frecuencias radioeléctricas» (las cursivas son mías). 
En quinto lugar, hay que tener en cuenta que el principio 12 de la Declaración de Principios sobre Libertad de Expresión de la OEA dispone que:

Los monopolios u oligopolios en la propiedad y control de los medios de comunicación deben estar sujetos a leyes antimonopólicas por cuanto conspiran contra la democracia al restringir la pluralidad y diversidad que asegura el pleno ejercicio del derecho a la información de los ciudadanos. En ningún caso esas leyes deben ser exclusivas para los medios de comunicación [...] (Comisión Interamericana de Derechos Humanos, 2000) ${ }^{24}$.

Así, no parece que pueda justificarse — sin apoyo en circunstancias fácticas concretas y racionales- que, de presentarse una situación de abuso de posición dominante el régimen general de defensa de la competencia - que supone tanto un control ex ante como ex post-, sea, per se, inapto para fomentar los fines que se persiguen en este campo (esto fue claramente señalado por el voto del juez Guarinoni en la sentencia de segunda instancia en el caso Grupo Clarín). Tal como lo señaló en la causa judicial un Amicus Curiae propuesto por la empresa impugnante, el régimen de defensa de la competencia argentino cuenta con los remedios aptos para prevenir y, en su caso, sancionar, conductas concretas que, a la par de ser anticompetitivas, impacten negativamente en el derecho a la información. Así, nada impide que, ante un caso concreto, la autoridad de defensa de la competencia pueda lidiar con precios predatorios o con ventas atadas, imponga la calificación de «essential facility» a una determinada facilidad necesaria para garantizar la competencia y pluralidad de operadores en el mercado audiovisual o, aun, que imponga, fundadamente, la obligación de desinversión para prevenir eventuales abusos del poder de mercado (Rodríguez Simón, 2013, pp. 315-325). Téngase en cuenta, además, que el régimen argentino de defensa de la competencia - a diferencia de lo que ocurre en otros países de la región- contempla, desde el año 1999, un estricto mecanismo de control ex ante de operaciones de concentración económica (fusiones y adquisiciones), aplicable a toda clase de empresas, sean estas «reguladas» o no. Por ello, debería haberse justificado que todos estos remedios — sancionatorios y preventivos - resultaban ineficaces para garantizar los fines perseguidos por la legislación y que, por lo tanto, resultaba necesario proceder a imponer restricciones sectoriales generales y ex ante como las contenidas en la LSCA.

24 Sobre el particular, la Relatoría para la Libertad de Expresión señaló lo siguiente: «No se impide entonces la existencia de un marco regulatorio antimonopólico que incluya normas que garanticen la pluralidad atendiendo la especial naturaleza de la libertad de expresión. En todo caso, a la luz del principio 12 los Estados no deben adoptar normas especiales bajo la apariencia de normas antimonopólicas para los medios de comunicación que en realidad tienen como propósito y efecto la restricción de la libertad de expresión" (OEA, 2004; las cursivas son mías).

¿REGULAR O

COMPETIR? EL

CASO DE LA LEY

DE SERVICIOS DE

COMUNICACIÓN

AUDIOVISUAL DE

LA REPÚBLICA

ARGENTINA Y EL

PRINCIPIO DE PRO-

PORCIONALIDAD

COMO CRITERIO

DELIMITADOR

¿REGULATION OR

COMPETITION?

THE CASE OF THE

ARGENTINE LAW

OF AUDIOVISUAL

COMMUNICATIONS

SERVICES AND

THE PROPORTIO-

NALITY PRINCIPLE

AS A DELIMITING

CRITERION 
En definitiva, no hay nada que indique, indubitablemente, ya desde el punto de vista de los principios, ya desde circunstancias concretas, que la concentración empresaria en el mercado audiovisual necesariamente deba derivar en una limitación a la diversidad y pluralidad de ideas e información o en la afectación de la competencia en dicho mercado. Tampoco hay nada que indique que, de producirse dicha concentración, una situación concreta de abuso de la situación de dominio aflictiva de todos estos valores, esta no pueda ser válida y eficazmente remediada por la aplicación del régimen de defensa de la competencia. Así, entendemos que la íntima relación que existe entre libertad de expresión y derecho de propiedad exige que cualquier intento de regulación directa y sectorial de este último sea justificado por el subprincipio de necesidad y no por un simple criterio de conveniencia ideológica o política. Dicha justificación debe brindar las razones por las que, en el caso en cuestión, el régimen de defensa de la competencia —o cualquier otra regulación menos intrusiva - resulta insuficiente para promover la pluralidad y diversidad informativa.

\section{VI.LA REGULACIÓN DE LA PROPIEDAD DE LOS MEDIOS DECOMUNICACIÓNYELPRINCIPIODE PROPORCIONALIDAD EN SENTIDO ESTRICTO}

El tercer subprincipio que integra el test de proporcionalidad es el llamado subprincipio de proporcionalidad en sentido estricto. En su formulación general, suele entenderse que este juicio supone balancear, por un lado, los beneficios que representa para el bien común la medida adoptada y, por otro, la restricción que ella impone a los derechos, de forma tal que pueda concluirse que los medios guardan una relación razonable con el fin buscado (Schwarze, 1992, p. 855; Barnes, 1994, p. 507; Blanke, 2009, p. 606; para el caso de la doctrina argentina y este subprincipio como el que propugna una relación razonable entre los medios y el fin perseguido, véase Cianciardo, 2009, p. 107). Fundados en el origen alemán del examen y en el aporte de Alexy, quien ha propugnado integrar dicha relación con su ley de la ponderación —basada en la idea de optimización de las posibilidades normativas de los principios - en el principio de proporcionalidad ${ }^{25}$, algunos autores han señalado que el juicio de proporcionalidad en sentido estricto equivale a una suerte de ponderación entre los beneficios y perjuicios generados por la medida (Blanke, 2009, p. 606; en Argentina, Linares, desde la perspectiva de la teoría egológica del derecho, fue pionero en referirse a la razonabilidad ponderativa como integrante del juicio de razonabilidad,

25 La ley de la ponderación ha sido enunciada por Alexy en los siguientes términos: «Cuanto mayor sea el grado de la no satisfacción o del detrimento de un principio, mayor debe ser la importancia de la satisfacción del otro". Sobre esto y su relación con el principio de proporcionalidad según este autor, véase Alexy (1993, pp. 91ss.; 2005, p. 573; 2005, pp. 61ss.). 
véase Linares, 1989, p. 143), aunque la proporcionalidad —se señala— no es solo ponderación. El propio Alexy ha reconocido que el principio de proporcionalidad es más amplio que el de ponderación (Alexy, 2005, p. 61; para una aplicación de esta afirmación al derecho administrativo, véase Rodríguez de Santiago, 2000, p. 111).

Más allá de la complejidad que entraña el análisis de este subprincipio y la base conflictivista entre derechos en que se sustenta, en nuestra opinión, el juicio de proporcionalidad en sentido estricto impone determinar si la decisión reguladora armoniza o no el interés general con el interés del afectado. Esto obliga a verificar si, en el caso concreto, la satisfacción del interés público que persigue la medida no se consigue a expensas de la afectación de la sustancia del derecho particular ni de terceros. Esta tarea implica la necesidad de determinar lo justo concreto para el caso.

Así, y asumiendo que el interés público —en cuanto bien común- es por esencia participable a todos los miembros de la comunidad (Soaje Ramos, 2005, p. 33; Finnis, 1980, p. 155) y en todo momento (Finnis, 1980, pp. 155, 214), no puede resultar justo que el interés público que sustentaría la medida reguladora pudiera aniquilar el bien particular de su destinatario o los bienes de otros sujetos, puesto que, entonces, el bien que se ha pretendido privilegiar no sería común (Soaje Ramos, 2005, p. 41). El bien común no constituye una realidad sustancial, sino una de orden (precisamente, esta es la diferencia que existe entre el realismo clásico y el totalitarismo en su concepción del fin del Estado, véase Soaje Ramos, 2005, pp. 39, 41), de modo tal que, para que aquel realmente se verifique, debe ordenar o armonizar los bienes particulares que presupone (Soaje Ramos, 2005, p. 41; Finnis, 1980, p. 155). La función del juicio de proporcionalidad está dada — desde esta perspectiva — en garantizar que esta armonización se verifique en el caso enjuiciado (Cianciardo, 2009 , p. 124). De allí que bien haya señalado Juan Carlos Cassagne lo siguiente:

[...] si se respeta el principio de no contradicción, nunca puede ser un criterio interpretativo válido darle preferencia dogmática a un principio sobre otro ni al derecho colectivo sobre el derecho individual, en la medida en que son derechos fundamentales de la persona humana. Ello implicaría negar de antemano el principio o derecho, despojándolo de su condición esencial. Lo que sí puede haber, y de hecho es lo que acontece, es que deba resolverse un conflicto entre pretensiones de partes que se apoyan en derechos que, en un determinado caso, aparecen enfrentados y en el que el juez deberá darle toda o parcialmente la razón a una u otra sobre la base de la ponderación y de las exigencias de la razonabilidad (2013, p. 785). 
De esta forma, cabe resaltar que la adecuada participación del bien particular en el bien común supone que la decisión estatal respete el contenido esencial ${ }^{26}$ o la sustancia (Cianciardo, 2009, pp. 146ss.) del derecho del particular, puesto que esta garantía permite, por un lado, evadir la falsa premisa de que se está en presencia de conflictos de derechos o de conflictos entre el interés general y el particular, así como la de ponderar — con las dificultades que ello implica- la importancia relativa de los derechos y, por otro lado, mantener vivo y eficaz el carácter no absoluto de estos últimos (Serna \& Toller, 2000, p. 42; Cianciardo, 2009, pp. 114ss.; sobre el carácter limitado de los derechos y su vinculación con la razonabilidad, véase Finnis, pp. 210ss.; acerca de cómo esta última postura puede ser utilizada como una alternativa frente al aparente conflicto de derechos y a la técnica del balance, véase Russman, 1981, pp. 296ss.). La sustancia o contenido esencial del derecho no es la frontera hasta la cual el Estado puede restringir el derecho, sino que, como bien se ha señalado, constituye el amplio ámbito de su ejercicio que, una vez definido en general y determinado en las circunstancias concretas del caso, no puede ser dejado de lado por razones utilitarias (Serna \& Toller, 2000, p. 47). Las verdaderas libertades no pueden ser abstractas sino concretas, razón por la cual se verifican con su ejercicio y respeto por la autoridad en casos precisos y reales ${ }^{27}$. Lo relevante no es tener o conocer cuáles son nuestros derechos, sino tener el derecho en el caso (Martínez Muñoz, 1996, p. 363; Finnis, 1980, p. 218). Por esta razón, la determinación del contenido esencial o sustancia del derecho —que es el válido ejercicio de este en el caso particular- solo puede determinarse en situaciones concretas (se trata de una tarea de determinación del derecho, véase Finnis, 1980, p. 218).

Así, tal como ha señalado Coviello, el ejercicio de la prudencia jurídica tiene particular relevancia en el juicio de proporcionalidad (2008). En este sentido, adviértase que el campo jurídico está ordenado solo a aquellas conductas estrictamente debidas para el logro del bien común (Massini Correas, 2006, p. 45), de modo tal que la función de la prudencia jurídica consiste en delimitar el contenido concreto de ese débito que es debido por una estricta razón de justicia (p. 46). Es, en definitiva, una virtud propia del acto de determinación de lo justo concreto con carácter definitivo (p. 46).

26 Como es sabido, la garantía del contenido esencial de los llamados derechos fundamentales es de raigambre europea y tiene su origen en la previsión contenida en el artículo 19 (2) de la Ley Fundamental para la República Federal de Alemania (1949) y ha sido también contemplada en el artículo 53.1 de la Constitución Española de 1978; sobre el particular, véase Häberle (2003, en especial, con vinculación al principio de proporcionalidad, pp. 67ss.), Martínez-Pujalte (1997, pp. 99ss.) y Sánchez Agesta (1991, pp. 211 y 214), entre muchos otros.

27 Uno de los principales legados negativos del racionalismo jurídico ha sido, precisamente, suplantar las históricas libertades concretas por declaraciones de libertades abstractas que, luego, son sistemáticamente desconocidas en los casos singulares (Millán Puelles, 1995, pp. 242ss). 
Si nos hemos permitido formular las consideraciones que anteceden, ello se debe a que la nueva visión sobre el derecho de la libertad de expresión en su aspecto colectivo, la cual la LSCA pretendió recoger, entraña el riesgo, precisamente, de entender que su optimización necesariamente impone el paralelo sacrificio del derecho que está en conflicto con él, en este caso, el derecho de propiedad de aquellos titulares de empresas de medios. Así, frente a una mayor jerarquía de la libertad de expresión que se asentaría en un interés público de orden primario, como sería la necesidad de fomentar la pluralidad y diversidad, fácil sería restringir - aunque no se lo extinguiese in totum — el derecho de propiedad de los titulares de medios de comunicación.

Como bien lo han señalado Bianchi y Sacristán, el criterio referido en el párrafo anterior fue el que utilizó la mayoría de la Corte Suprema argentina para validar las restricciones impuestas por la LSCA a las empresas de medios en su aplicación al caso Grupo Clarín. Bien refieren estos autores que no solo la propiedad que ejercía dicho grupo empresario sobre sus licencias se disoció de la libertad de expresión que se ejerce a través de la titularidad de ellas, sino que, además, una vez reducido el caso a una simple cuestión patrimonial, y previa adopción de un sistema abstracto de jerarquización entre derechos, el resultado no podía ser otro que la validación de la norma, tal como ocurrió (Bianchi \& Sacristán, 2014, p. 7).

Para los jueces Lorenzetti y Highton de Nolasco, la pérdida de la propiedad de las licencias en aras del interés superior de la promoción del derecho colectivo a la libertad de expresión era reemplazable — según los estándares de la responsabilidad estatal por su obrar lícito- por una mera compensación económica (Corte Suprema de Justicia de la Nación Argentina, 2013, considerando 66 del voto de los jueces Lorenzetti y Highton de Nolasco). Por el contrario, para los jueces Maqueda, Argibay y Fayt, dado que la propiedad sobre tales licencias constituía el modo en que se ejercía la libertad de expresión por parte del Grupo Clarín, estas no podían ser reemplazadas por una simple compensación económica. De allí que los dos primeros magistrados resolviesen que el Grupo Clarín debía mantener las licencias hasta su vencimiento, momento a partir del cual deberían ajustarse a los límites establecidos por la LSCA en la materia, y los tres últimos, lisa y llanamente, considerasen inconstitucional la regulación porque afectaba el contenido esencial del derecho de propiedad (véase el análisis pormenorizado de estos votos en: Bianchi \& Sacristán, 2014).

En nuestra opinión, como ya lo hemos señalado, no cabe reducir la propiedad sobre licencias o empresas de medios a una pura cuestión patrimonial y, viceversa, la libertad de expresión no tiene aplicación práctica si no se ejerce por medio de la titularidad de tales empresas

¿REGULAR O

COMPETIR? EL

CASO DE LA LEY

DE SERVICIOS DE

COMUNICACIÓN

AUDIOVISUAL DE

LA REPÚBLICA

ARGENTINA Y EL

PRINCIPIO DE PRO-

PORCIONALIDAD

COMO CRITERIO

DELIMITADOR

¿REGULATION OR

COMPETITION?

THE CASE OF THE

ARGENTINE LAW

OF AUDIOVISUAL

COMMUNICATIONS

SERVICES AND

THE PROPORTIO-

NALITY PRINCIPLE

AS A DELIMITING

CRITERION 
o licencias. Propiedad de licencias o medios y libertad de expresión son, en definitiva, las dos caras de una misma moneda. De allí que el juicio de proporcionalidad, en sentido estricto, no pueda ser realizado en abstracto sino, como hemos dicho, en concreto. Y lo que surge in concreto es que ambos derechos pueden ser armonizados, especialmente cuando de lo que se trata es de la posibilidad de prestar servicios que no se apoyan en espectro radioeléctrico (Corte Suprema de Justicia de la Nación Argentina, 2013, voto del juez Fayt). Por otra parte, aun cuando se admitiese la necesidad de establecer limitaciones a la cuota de mercado, la inmediata obligación de desinversión — con su exclusiva contrapartida en el pago de una compensación pecuniariaparece excesiva o desproporcionada en función de los beneficios que teóricamente podrían obtenerse de la aplicación inmediata de la medida.

Igualmente, y ahora desde una perspectiva de «análisis costo-beneficio», integrante, también, del juicio de proporcionalidad en sentido estricto, cabe aquí volver a recordar cuestionamientos que hemos realizado antes. Algunos de dichos cuestionamientos son las desventajas que la desintegración de economías de escala en empresas de medios producirían para la introducción de una verdadera pluralidad de operadores así como los perjuicios que sufrirían los usuarios de estos servicios en razón del encarecimiento de precios al que llevaría el incremento de costes, producto de la apuntada destrucción de la escala empresaria ${ }^{28}$.

\section{CONCLUSIONES}

Hemos intentado brindar algunas reflexiones sobre la aplicación del principio de proporcionalidad en materia de regulación de la propiedad de medios de comunicación audiovisual, especialmente sobre la base del caso argentino, intentando demostrar las complejidades que la aplicación de este principio presenta en esta materia, en la que libertad de expresión y propiedad, aparentemente contradictorias y en conflicto, tienen una relación inescindible. Existe, entonces, la necesidad de armonizar ambos derechos, porque en estos casos constituyen las dos caras de la misma moneda. Desde esta perspectiva, en industrias como la audiovisual, donde las economías de escala son necesarias para innovar, competir y para no supeditar la supervivencia de las empresas de medios a los favores estatales, la regulación directa del poder de mercado entraña el riesgo cierto de afectar la sostenibilidad de aquellas y de crear barreras de entrada a posibles nuevos prestadores. Esto impediría, en definitiva, que exista una real pluralidad y diversidad de ideas e información. Si regular

28 Al respecto, repárese en que, según surge del fallo de la segunda instancia, el dictamen pericial había señalado que «la reducción de actividades conforme a la ley no ocasionaría ningún beneficio a los usuarios. Al contrario, haría a los servicios más onerosos dado que se reducirían los beneficios de las economías de escala". 
suprimiendo la competencia posible en un mercado nunca es la opción correcta, mucho menos parece serlo en el mercado audiovisual.

Por ello, resulta más que cuestionable que la limitación a los derechos de propiedad que se estableció de modo directo, ex ante y sectorial por la LSCA cuente con suficiente respaldo en el principio de proporcionalidad. Resulta cuestionable que dicha regulación sea adecuada para lograr los fines de promoción de la diversidad y pluralidad de ideas e información que dice perseguir; que sea necesaria frente a la alternativa de someter a las empresas prestadoras a la competencia posible en el sector, sujetándolas a los remedios del régimen general de protección de la libre competencia; y que, en definitiva, armonice los derechos en juego, garantizando el contenido esencial de todos estos. Queda claro que, en este campo, no solo está en juego la protección de derechos particulares individuales y colectivos, sino, también, las bases de la democracia misma. No cabe olvidar que, aún hoy, y en estos nuevos contextos de la llamada sociedad de la información, continúa plenamente vigente aquello que casi dos siglos atrás dijera Tocqueville respecto del rol de la libertad de prensa frente al nuevo despotismo:

Creo que los hombres que viven en las aristocracias pueden, en rigor, pasarse sin la libertad de prensa, pero no los que habitan en los países democráticos. Para garantizar la independencia personal de estos no confío en las grandes asambleas políticas, en las prerrogativas parlamentarias, ni en que se proclame la soberanía del pueblo. Todas estas cosas se concilian hasta cierto punto con la servidumbre individual; mas esta esclavitud no puede ser completa si la prensa es libre. La prensa es, por excelencia, el instrumento democrático de la

¿REGULAR O COMPETIR? EL CASO DE LA LEY DE SERVICIOS DE COMUNICACIÓN AUDIOVISUAL DE LA REPÚBLICA ARGENTINA Y EL PRINCIPIO DE PROPORCIONALIDAD COMO CRITERIO DELIMITADOR

¿REGULATION OR COMPETITION? THE CASE OF THE ARGENTINE LAW OF AUDIOVISUAL COMMUNICATIONS SERVICES AND THE PROPORTIONALITY PRINCIPLE AS A DELIMITING CRITERION libertad (1996, p. 638).

\section{BIBLIOGRAFÍA}

Agesta, Luis Sánchez (1986). Principios cristianos del orden político. Buenos Aires: Temática.

Alexy, Robert (1993). Teoría de los derechos fundamentales. Madrid: Centro de Estudios Constitucionales

Alexy, Robert (2002). Epílogo a la Teoría de los derechos fundamentales. Revista Española de Derecho Constitucional, 22 (66), 13-64.

Alexy, Robert (2005). Balancing, constitutional review and representation. International Joumal of Constitutional Law, 3(4), 572-581. http://dx.doi. org/10.1093/icon/moi040

Alexy, Robet (2005). Teoría del discurso y derechos constitucionales. México D.F.: Fontamara. 
Ariño Ortiz, Gaspar, Juan Miguel de la Cuétara \& Iñigo del Guayo Castilla (2012). Regulación económica. Lecturas escogidas. Madrid: Thomson ReutersAranzadi.

Badeni, Gregorio (2010). Tratado de Derecho Constitucional. Tomo II. Tercera edición. Buenos Aires: La Ley.

Baldwin, Robert \& Martin Cave (1999). Understanding Regulation. Theory, Strategy and Practice. Oxford: Oxford University Press.

Barnes, Javier (1994). Introducción al principio de proporcionalidad en el derecho comparado y comunitario. Revista de Administración Pública, 135, 495-538.

Bazán, José Luis \& Raúl Madrid (1991). Racionalidad y razonabilidad en el Derecho. Revista Chilena de Derecho, 18(2), 179-188.

Becerra, Martín (2015). De la concentración a la convergencia. Políticas de medios en Argentina y América latina. Buenos Aires: Paidós.

Bianchi, Alberto (1991). La Corte Suprema ha establecido su tesis oficial sobre la emergencia económica. Revista La Ley, 1991-C-141.

Bianchi, Alberto \& Estela B. Sacristán (2014). El caso «Grupo Clarín». Una versión debilitada del control de constitucionalidad y de los derechos adquiridos. El Derecho Constitucional, 52(13.431), 20 de febrero, 1-9.

Bidart Campos, Germán J. (1968). Derecho constitucional. Realidad, normatividad y justicia en el derecho constitucional. Buenos Aires: Ediar.

Blanke, Hermann Josef (2009). El principio de proporcionalidad en el derecho alemán, europeo y latinoamericano. Revista de Derecho Administrativo, 9, 343-351.

Breyer, Stephen (1982). Regulation and its reform. Cambridge: Harvard University Press.

Cassagne, Juan Carlos (2013). El neoconstitucionalismo y su proyección al acto administrativo. Derecho Administrativo. Revista de Doctrina, Jurisprudencia, Legislación y Práctica, 87, 757-786.

Cianciardo, Juan (2009). El principio de razonabilidad. Del debido proceso sustantivo al moderno juicio de proporcionalidad. Segunda edición. Buenos Aires: Ábaco.

Coalición por una Radiodifusión Democrática (s/f). Hacia una nueva Ley de Radiodifusión. 21 Puntos básicos por el derecho a la comunicación. http://www. telam.com.ar/advf/imagenes/especiales/documentos/2012/11/509435587ec92. pdf.

Coase, Ronald H. (1988). La Comisión Federal de Comunicaciones. En La empresa, el mercado y la ley (pp.79-119). Madrid: Alianza Editorial.

Coloma, Germán (2003). Defensa de la Competencia. Buenos Aires-Madrid: Ciudad Argentina. 
Comisión Interamericana de Derechos Humanos (1969). Convención Americana sobre Derechos Humanos (Pacto de San José). Convención suscrita en Conferencia especializada interamericana sobre derechos humanos (B-32). San José, Costa Rica, 7-22 de noviembre.

Comisión Interamericana de Derechos Humanos (2000). Declaración de Principios sobre Libertad de Expresión. Declaración adoptada por la Comisión Interamericana de Derechos Humanos en su 108 período ordinario de sesiones celebrado del 2 al 20 octubre de 2000. http://www.oas.org/es/cidh/mandato/ Basicos/PrincipiosLE.asp.

Constitución de la Nación Argentina (1853).

Constitución Española (1978).

Corte Interamericana de Derechos Humanos (1985). La colegiación obligatoria de periodistas. Opinión consultiva OC-5/85 del 13 de noviembre de 1985. Seria A número 5.

Corte Interamericana de Derechos Humanos (2001). Caso Ivcher Bronstein vs. Perú. Sentencia de 6 de febrero de 2001 (reparaciones y costas). Serie C número 74.

Corte Interamericana de Derechos Humanos (2008). Caso Salvador Chiriboga vs. Ecuador. Sentencia de 6 de mayo de 2008 (excepción preliminar y fondo). Serie C número 179.

Corte Interamericana de Derechos Humanos (2012). Caso Furlán y Familiares vs. Argentina. Sentencia de 31 de agosto de 2012 (excepciones preliminares, fondo, reparaciones y costas). Serie C número 246.

Corte Suprema de Justicia de la Nación Argentina (1999). Ríos Rubén Francisco contra Estado Nacional-COMFER-Dirección Nacional de Telecomunicaciones s/ordinario-Acción de inconstitucionalidad. Fallo del 1 de noviembre. Expediente R. 30. XXXV. REX.

Corte Suprema de Justicia de la Nación Argentina (2003). Asociación Mutual Carlos Mujica contra Estado Nacional (Poder Ejecutivo Nacional-COMFER) s/amparo. Fallo del 1 de setiembre. Expediente A. 215. XXXVII. REX.

Corte Suprema de Justicia de la Nación Argentina (2013). Grupo Clarín SA y otros c/ Poder Ejecutivo Nacional y otro s/acción meramente declarativa. Sentencia del 29 de octubre. Expediente G. 439. XLIX. REX.

Corte Suprema de los Estados Unidos de América (1943). National Broadcasting Co. v. United States. 319 U.S. 190 (1943).

Corte Suprema de los Estados Unidos de América (1945). Associated Press v. United States. 326 U.S. 1 (1945).

Corte Suprema de los Estados Unidos de América (1969a). Citizen Publishing Company v. United States. 394 U.S. 131 (1969).

Corte Suprema de los Estados Unidos de América (1969b). Red Lion Broadcasting Co. v. Federal Communications Commission. 395 U.S. 367 (1969). 
Coviello, Pedro José Jorge (2008). El principio de razonabilidad en el derecho público argentino. En Carlos Delpiazzo (coord.), Estudios jurídicos en homenaje al Prof. Mariano R. Brito (pp. 419-440). Montevideo: Fundación de Cultura Universitaria.

Fernández Ordóñez, Miguel A. (2000). La competencia. Madrid: Alianza Editorial.

Finnis, John (1980). Natural Law and Natural Rights. Oxford: Oxford University Press.

Finnis, John (1998). Aquinas. Moral, political and legal theory. Oxford: Oxford University Press.

Fiss, Owen (1999). La ironía de la libertad de expresión. México D.F.: Gedisa.

Grenfell, Michael (1999). Can competition law supplant utilities regulation? En Christopher McCrudden (ed.), Regulation and deregulation. Policy and practice in the utilities and financial services industries (pp. 221-234). Oxford: Oxford University Press.

Grondona, Mariano Florencio (1986). La reglamentación de los derechos constitucionales. Teoría del orden de derechos. Buenos Aires: Depalma.

Grondona, Mariano Florencio (2004). Exámenes de constitucionalidad. Revista La Ley, 2004-D-1235.

Häberle, Peter (2003). La garantía del contenido esencial de los derechos fundamentales. Madrid: Dykinson.

Haro, Ricardo (2003). El control de constitucionalidad. Buenos Aires: Zavalía.

Huapaya Tapia, Ramón (2011). Algunos apuntes sobre las relaciones entre el derecho administrativo económico y el concepto anglosajón de la regulación. En Administración pública, derecho administrativo y regulación. Estudios y cuestiones. Lima: ARA Editores.

Kaufman, Gustavo Ariel (1991). Constitucionalidad del avasallamiento consumado: el caso «Peralta». El Derecho, 146.

Ley Fundamental para la República Federal de Alemania (1949).

Linares, Juan Francisco (1989). La razonabilidad de las leyes. Buenos Aires: Astrea.

Littlechild, Stephen (2002). Chairman's comments. En Colin Robinson (ed.), Utility regulation and competition policy (pp. 96-98). Londres: Institute of Economic Affairs.

Loreti, Damián (2014). Libertad de expresión y radiodifusión. En Julio César Rivera y otros (dirs.), Tratado de los derechos constitucionales, tomo II. Buenos Aires: Abeledo Perrot. 
Loreti, Damián \& Luis Lozano (2014). El derecho a comunicar. Los conflictos en tormo a la libertad de expresión en las sociedades contemporáneas. Buenos Aires: Siglo XXI.

Martínez Muñoz, Juan Antonio (1996). Derechos y libertades fundamentales: garantías y participación. En autores varios, El Estado de derecho en la España de hoy (pp. 349-386). Madrid: Actas-Sección de Filosofía del Derecho en la Real Academia de Jurisprudencia y Legislación.

Martínez-Pujalte, Antonio-Luis (1997). La garantía del contenido esencial de los derechos fundamentales. Madrid: Centro de Estudios Constitucionales.

Massini Correas, Carlos Ignacio (2006). La prudencia jurídica. Introducción a la gnoseología del derecho. Segunda edición. Buenos Aires: Lexis Nexis.

Millán Puelles, Antonio (1995). El valor de la libertad. Madrid: Rialp.

Ogus, Anthony I. (2004). Regulation: legal form and economic theory. OxfordPortland: Hart Publishing. http://dx.doi.org/10.5040/9781472559647

Organización de los Estados Americanos (2000). Informe anual del Relator Especial para la Libertad de Expresión.

Organización de los Estados Americanos (2004). Informe anual del Relator Especial para la Libertad de Expresión.

Orlanski, Leonardo T. (2006). Competencia y regulación. Buenos Aires: Ad Hoc.

Padilla, Miguel M. (1984). Razonabilidad jurídica y razonabilidad técnica. Revista La Ley, 1984-C-1106.

Presidencia de la Nación Argentina (1972). Ley Nacional de Telecomunicaciones. Ley 19798. Boletín Oficial de la República Argentina, 80(22.489), 23 de agosto, 2-7.

Presidencia de la Nación Argentina (1980). Ley de Radiodifusión. Ley 22285. Boletín Oficial de la República Argentina, 88(24.506), 19 de setiembre, 2-8.

Presidencia de la Nación Argentina (2015). Ente Nacional de Comunicaciones. Decreto 267/2015. Creación. Ley 26522 y 27078. Modificaciones. Buenos Aires, 29 de diciembre. Boletín Oficial de la República Argentina, 124(33.288), 4 de enero de 2016, 9-12.

Rodríguez de Santiago, José María (2000). La ponderación de bienes e intereses en el derecho administrativo. Madrid: Marcial Pons.

Rodríguez Simón, Fabián (2013). Clarín y la Ley de Medios. Buenos Aires: Planeta.

Russman, Thomas (1981). Balancing rights: the modern problem. Catholic Lawyer, 26(4), 296-306.

Sacristán, Estela B. (2005). Control judicial de las medidas de emergencia (A propósito del análisis costo-beneficio). En Guillermo Scheibler (coord.), 
El derecho administrativo de la emergencia, volumen IV (pp. 111-140). Buenos Aires: Fundación de Derecho Administrativo.

Samuelson, Paul A. \& William D. Nordhaus (1998). Economía. Décimo quinta edición. Madrid: Mc Graw Hill.

Sánchez Agesta, Luis (1991). Sistema político de la Constitución española de 1978. Sexta edición. Madrid: Revista de Derecho Privado.

Schwarze, Jürgen (1992). European Administrative Law. Londres: Sweet \& Maxwell.

Secretaría General de la Unión Internacional de Telecomunicaciones (1982). Convenio Internacional de Telecomunicaciones. Ginebra: UIT.

Senado y Cámara de Diputados de la Nación Argentina (1986). Apruébase el Convenio Internacional de Telecomunicaciones adoptado en Nairobi, Kenya. Ley 23478, sancionada el 31 de octubre y promulgada el 1 de diciembre. Boletín Oficial de la República Argentina, 95(26.131), 23 de abril de 1987, 1-20.

Senado y Cámara de Diputados de la Nación Argentina (1999). Defensa de la Competencia. Ley 25156, Acuerdos y prácticas prohibidas. Posición dominante. Concentraciones y Fusiones. Autoridad de aplicación. Presupuesto del Tribunal Nacional de Defensa de la Competencia. Procedimiento. Sanciones. Apelaciones. Prescripción. Disposiciones transitorias y complementarias, sancionada el 25 de agosto y promulgada el 16 de setiembre. Boletín Oficial de la República Argentina, 107(29.233), 20 de setiembre, 5-13.

Senado y Cámara de Diputados de la Nación Argentina (2005). Radiodifusión. Ley 26053, sustitúyese el artículo 45 de la ley 22285, sancionada el 17 de agosto y promulgada el 14 de setiembre. Boletín Oficial de la República Argentina, 93(30.739), 15 de setiembre, 1-2.

Senado y Cámara de Diputados de la Nación Argentina (2009). Servicios de Comunicación Audiovisual. Ley 26522, regúlanse los Servicios de Comunicación Audiovisual en todo el ámbito territorial de la República Argentina, sancionada y promulgada el 10 de octubre. Boletín Oficial de la República Argentina, 97(31.756), 10 de octubre, 1-25.

Senado y Cámara de Diputados de la Nación Argentina (2011). Pasta celulosa y papael para diarios. Ley 26736, sancionada el 22 de diciembre y promulgada el 27 de diciembre. Boletín Oficial de la República Argentina, 119(32.305), 28 de diciembre, 1-3.

Serna, Pedro \& Fernando Toller (2000). La interpretación constitucional de los derechos fundamentales. Una alternativa a los conflictos de derechos. Buenos Aires: La Ley.

Soaje Ramos, Guido (2005). Sobre la politicidad del derecho. El bien común político. En Sergio R. Castaño y Eduardo Soto Kloss (eds.), El derecho natural en la realidad social y jurídica. Santiago de Chile: Academia de Derecho, Universidad Santo Tomás.

Sola, Juan Vicente (2004). Constitución y economía. Buenos Aires: Lexis Nexis. 
Stelzer, Irwin M. (2002). A review of privatization and regulation experience in the UK. En Colin Robinson (ed.), Utility regulation and competition policy (pp. 82-95). Londres: Institute of Economic Affairs.

Tau Anzoátegui, Carlos A. (2001). Régimen jurídico de las telecomunicaciones y la radiodifusión. Buenos Aires: La Ley.

Tocqueville, Alexis de (1996). La democracia en América. México D.F.: Fondo de Cultura Económica.

UNESCO ([1980] 1987). Un solo mundo, voces múltiples. Comunicación e información en nuestro tiempo. Informe de la Comisión Internacional para el Estudio de los Problemas de la Comunicación redacto por Sean MacBride y otros. México D.F.: Fondo de Cultura Económica.

Veljanosvki, Cento (2006). The economics of law. Segunda edición. Londres: Institute of Economic Affairs.

Vickers, John (1996). Competition and regulation. The UK experience. En Michael Beesley (ed.), Regulating utilities: a time for change? (pp. 91-105). Londres: Institute of Economic Affairs.

Viscusi, W. Kip \& otros (2000). Economics of regulation and antitrust. Tercera edición. Cambridge: The MIT Press.

¿REGULAR O

COMPETIR? EL

CASO DE LA LEY

DE SERVICIOS DE

COMUNICACIÓN

AUDIOVISUAL DE

LA REPÚBLICA

ARGENTINA Y EL

PRINCIPIO DE PRO-

PORCIONALIDAD

COMO CRITERIO

DELIMITADOR

¿REGULATION OR

COMPETITION?

THE CASE OF THE

ARGENTINE LAW

OF AUDIOVISUAL

COMMUNICATIONS

SERVICES AND

THE PROPORTIO-

NALITY PRINCIPLE

AS A DELIMITING

CRITERION 